\title{
Uma Reflexão Acerca do Núcleo Fundamental da Teoria Contábil
}

\author{
Alberto Weimann Gergull \\ Mestrando em Controladoria e Contabilidade pela FEA/USP \\ Consultor da SOMA Consultores S/C
}

INTRODUCÃO

Este século tem sido marcado por um dinâmico movimento de transformações nas relações humanas, em ciclos sistêmicos cada vez mais estreitos e retroalimentados impactado principalmente pelo aspectos qualitativos destas transformações, cujo efeito se faz especialmente presente no ambiente que cerca as organizações.

Como conseqüência novos desafios emergem, ampliando as fronteiras dos relacionamentos com o meio exigindo em síntese: uma percepção, mais acurada da realidade, como pré condição para a sobrevivência.

É importante notar que a impressa em ao eixo destes ciclos realça e repele com vigor os desajustes ás regras dos grande jogo travado no ambiente.

$\mathrm{Na}$ esteira desta revolução, inúmeras teorias, métodos e técnicas vem sendo desenvolvidos como forma de resposta aos desafios imediatos, porém (em grande numero) com efeitos tópicos e nem sempre engendrados na nova realidade que se apresenta: essencialmente a mesa, entretanto muito mais veloz na resposta aos estímulos introduzidos ao meio, o que requer maior ajuste, equilíbrio, sintonia ambiental. Pequenos desajustes serão cada vez mais intolerados.

Ao mesmo tempo em que se observa esta realidade no campo da Administração, o que pode ser dito acerca da Contabilidade, ressalvado o fato de vir procurando suprir todo este processo das informações requeridas, através da Contabilidade Gerencial?

Depois da grande quebra da bolsa de New York em 1929, da enunciação de princípios, elaboração de guias e regras que visam, a grosso modo, disciplinar a retratação do passado pelo Contador, e a "previnir" (?!) a perpetração de fraudes, em que mais a Contabilidade pode evocar testemunho de uma evolução em direção a esta nova/antiga realidade?

E quanto à Estrutura Teórica Fundamental da Contabilidade? Ela constitui-se no pilar da Contabilidade como ela hoje se apresenta, posto que desenvolvida com esta finalidade precípua. Oportunamente será demonstrada na seqüência deste trabalho.

Dentro deste cenário, entende-se haver algo de ajuste a ser requerido no conjunto de Princípios de Contabilidade Geralmente Aceitos, ou Princípios de Contabilidade, ou ainda, Princípios "Preferências" de Contabilidade, ou como se queira denominar.

O objetivo deste artigo é de desenvolver um questionamento de Estrutura Conceitual Básica da Contabilidade, procurando revelar os fundamentos da atitude contábil excessivamente conservadora, fixada no passado e, através da inserção do Postulado do Ambiente, no conjunto dos postulados da Contabilidade, buscar o redirecionamento do seu foco para a dinâmica ambiental.

$\mathrm{Na}$ leitura Bertalanffy ${ }^{1}$, encontra-se a seguinte "pérola", e que de certa forma deu origem a este trabalho:

"Qualquer sistema enquanto entidade que pode ser usada em si mesma deve ter limites, quer espaciais quer dinâmicos. Estritamente falando, as fronteiras espaciais só existem na observação

\footnotetext{
${ }^{1}$ BERTALANFFY, Ludwing von. Teoria Geral dos Sistemas. Petrópolis: Vozes: 1977, p. 286.
} 
ingênua, pois todas as fronteiras são, em ultima analise, dinâmicas. Não é possível traçar exatamente os limites de um átomo (com Valência, saltando para fora, por assim dizer, para atrair outros átomos), de uma pedra (agregado de moléculas e átomos que consiste em sua maior parte um espaço vazio com partículas situadas á distância planetárias), ou de um organismo que esta continuamente trocando matéria com o meio".

Como é possível notar, Bertalanffy, refere-se a entidade como um agente sistêmico. Para a Contabilidade, Entidade é o primeiro postulado, em que se assenta toda a fundamentação teórica de forma dedutiva.

Pergunta-se: em que pode aproximar ou diferir, o conceito Entidade de Bertalanffy e aquele adotado pela Contabilidade? Em resposta verifica-se que a Contabilidade reconhece limites ou fronteiras muito nítidas à Entidade objeto de sua observação, como a que negar todo o relacionamento sistêmico inerente ao ambiente que a cerca.

Por outro lado, os objetivos da Contabilidade estão declaradamente muito concentrados em informar e a um usuário ainda desconhecido. E como fica o estudo de seu ambiente, preocupação primária dos demais campos científicos?

Nesta linha de pensamento procura-se conduzir a seqüência deste trabalho.

\section{A Evolucão da Ciência Contábil e seu Caráter Utilitário}

A ciência encontra normalmente o impulso de sua evolução atrelado aos ciclos de expansão econômica, seja pelo aproveitamento das revelações em aplicações tecnológica, aporte de recursos ou pela demanda gerada pelas necessidades práticas de solução. Da mesma forma, o desenvolvimento cientifico tem propiciado esteio para o desenvolvimento econômico, como demonstram as inúmeras aplicações tecnológicas desenvolvidas concomitantemente com as descobertas iniciadas a parti do renascimento europeu.

Needham (citado por Barnes ${ }^{2}$, Kuhn, Merton y Otros), estudioso da Sociologia da Ciência, oferece seu depoimento sobre este período, que tem especial interesse por suas referencias ao desenvolvimento da Contabilidade:

"(...) porém, o desenvolvimento da ciência moderna na Europa, nos séculos XVI e XVII, ou bem deve ser explicado, ainda que seja de maneira aproximada e por tentativa. Esse desenvolvimento não foi um fenômeno isolado, ocorrei pari passu com o Renascimento, a Reforma e o surgimento do Capitalismo mercantil seguido pela manufatura industrial. Talvez, mudanças sociais e econômicas concomitantes que sobreviveram apenas na Europa, tenham constituído o ambiente em que as ciências naturais puderam elevar-se finalmente acima do nível do artesanato superior e dos técnicos semimatemáticos. A redução de toda a quantidades, a afirmação de uma realidade matemática que estava atrás de todas as aparências, a proclamação de um espaço e um tempo uniformes em todo o Universo, não foi tudo isso algo análogo à padronização do valor pelo comerciante? (...) Disto há abundantes provas entre nossos matemáticos. A primeira exposição escrita da técnica de Contabilidade de partida dobrada se acha melhor texto de matemática de que se dispunha no século XVI, a Summa de Arithmetica (1494) de Luca Pacioli. A primeira aplicação da contabilidade de partida dobrada aos problemas das finanças e à administração publica se fez nas obras do engenheiro-matemático Simon Stevin (1608). Até o Copérnico escreveu sobre a reforma monetária (em sua Moneta Cudenda e Ratio, de 1552) ".

O relato de diversos autores, incluindo ludicibus ${ }^{3}$. rranco $^{4}$, Moonitz $^{5}$ Most $^{6}$, Hendriksen $^{7}$, dentre

\footnotetext{
${ }^{2}$ BARNES Barry, KUHN, Thomas S., MERTON, Robert K. e Ottos. Estudos sobre Sociologia de La Ciencia. Madrid: Alianza Editorial S.A., 1980, p. 43.

${ }^{3}$ IUDíCIBUS, Sérgio de. Teoria da Contabilidade. São Paulo: Atlas, 1980.

${ }^{4}$ FRANCO, Hilário. A Evolução dos Princípios Contábeis no Brasil. São Paulo: Atlas, 1988.
} 
os autores pesquisados confirma que a Contabilidade teve como principal motor de sua evolução o enfrentamento de demandas da atividade econômica, nas diversas fases de seu desenvolvimento, podendo ser resumidas as principais influencias, como segue:

- do Renascimento ate inicio do século XIX, a demanda por informes gerenciais - neste período o desenvolvimento da Contabilidade esteve a cargo da escola Européia, origem da disciplina;

- a partir do surgimento das sociedades anônimas mais complexas no século XIX e decorrentes da necessidade de grandes aportes de capital, acrescem-se as primeiras necessidades, a geração de informes aos acionistas e credores, e ainda ao governo, este ultimo principalmente interessado na cobrança do imposto sobre a renda, nascida em finais desse século;

- no século XIX e princípios do século XX, com a revolução industrial e surgimento das grandes plantas de produção, tem-se o desenvolvimento da Contabilidade de Custos, e o reconhecimento da depreciação. como decorrência de problemas derivados da tratativa contábil das operações com ferrovias;

- com o crescimento da economia norte-americana, impulsionado pela crise das bolsas de 1929, inicia-se um amplo programa de pesquisas e disciplina da atividade contábil naquele pais, com grande preocupação em propiciar a compreensão e um corpo teórico consistente às praticas contábeis adotadas. dando inicio a ascensão da escola americana.

Pode-se afirmar que muito pouco das práticas contábeis foram originadas do desenvolvimento teórico da Contabilidade, senão que foi percorrido o caminho inverso, na necessidade de justificar e uniformizar as soluções encontradas na pratica. Não se questiona as soluções encontradas, e sim, evidencia-se a forma como as mudanças e o crescimento da Contabilidade tem se processado historicamente.

Apesar do desenvolvimento experimentado desde a entrada da Escola Americana, fica evidente o caráter utilitário Contábil, subserviente a manutenção de Soluções encontradas para problemas experimentados no passado: grandemente preocupada com aspectos do conservadorismo e atendimento de necessidades fiscais.

A partir dos grandes problemas apresentados para os quais a Contabilidade reagiu e encontrou soluções satisfatórias, pelo menos amplamente aceitas, não parece haver existido uma evolução significativa, afora aperfeiçoamentos tópicos, que não representam relevantes mudanças de enfoque. A Contabilidade parece ter estancado o seu desenvolvimento, comparativamente ao avanço experimentado por outros campos do conhecimento e ao extraordinário dinamismo ambiental.

A Contabilidade vem confirmando a sua vocação para a reação às demandas externas, tendo o foco projetado para o passado e não para o futuro. de forma a antecipar as tendências e determinar a sua própria demanda.

Reproduz-se, a seguir, uma passagem de Hendriksen ${ }^{8}$, em que estas preocupações são colocadas em realce:

"Em todas as disciplinas, as teorias e conceitos se desenvolvem em continuidade histórica. Um pensamento conduz a outro. Onde estamos hoje depende em boa parte de onde estivemos ontem. De fato, muitas das coisas feitas baseiam-se em razões que deixaram de ser pertinentes; até temos perdido de vista muitas das razões e continuamos da mesma forma por resistência à mudança. Esta exige uma consideração de onde estamos e para onde iremos. No mundo da prática da

\footnotetext{
${ }^{5}$ MOONITZ, Maurice. Obtaining Agreement on Standards in the Accounting Profession, Studies in Accounting Research, N. 8. Sarasota: American Accounting Association, 1974.

${ }^{6}$ MOST, Kenneth. Accounting Theory, 3 ed. Illions: Richard Irwin, 1977.

${ }^{7}$ HENDRISKEN, Eldon S. Teoria de la Contabilidad. México: Union Tipográfica Editorial Hispan-Americano, 1970.

${ }^{8}$ HENDRISKEN, Eldon S. Op. Cit.., p. 25.
} 
Contabilidade, os contadores geralmente carecem de tempo para deter-se e avaliar as razões de suas práticas. O termo "sabedoria convencional' cunhado por Galbraith é muito apropriado para ser aplicado à Contabilidade. "Sabedoria convencional" é o conhecimento obtido porque geralmente aceito; os desvios a respeito dessa "sabedoria convencional" nem sempre encontram aceitação, nem sequer quando justificados plenamente. Pode-se exigir que um auditor independente negue um certificado limpo porque as demonstrações financeiras não". estão preparadas 'de acordo com princípios de Contabilidade geralmente aceitos'. Se bem que a sabedoria convencional' não tem por necessidade brindar o fundamento mais útil da teoria atual, não podemos negar que o pensamento e a prática contábeis atuais são influenciados pelos acontecimentos passados".

O núcleo fundamental da Teoria Contábil e determinado pelos objetivos, postulados princípios e restrições ou convenções.

\section{O Núcleo Fundamental da Teoria Contábil}

Esta fase atem-se para a analise dos postulados, estando os princípios e restrições fora do escopo desta proposição.

A ciência interessa-se primariamente pelo estudo do universo como um todo. Dada a vastidão de seus domínios, o estudo cientifico procede à segregação de áreas de interesse, de forma a organizar a atividade de pesquisa, disciplinar o deslumbramento do cientista perante o mundo. Esta segregação obedece a atributos relevantes observados no ambiente de interesse de cada ramo de estudo cientifico. Sua revelação e a orientação primaria do interesse cientifico em dado campo de conhecimento constitui-se na missão dos postulados.

Os postulados são pré existentes a própria ciência, são permanentes ou imutáveis. e cumprem a finalidade de servirem de referencial a observação do pesquisador na condução de seus estudos tal como a lei de gravidade o representa para física, ou a lei da oferta e da procura serve de referencial para o economista. Os princípios e restrições decorrem do alicerce previamente erigido pelos postulados nesta ordem. $\mathrm{Na}$ categoria das restrições entende-se como classificadas as chamadas normas e guias de orientação conforme se apresentam na Contabilidade.

Não existe consenso entre as autoridades Teoria Contábil sobre a hierarquização e classificação que deva ser dada aos princípios contábeis, genericamente denominados postulados princípios e restrições. Segundo ludícibus " “(...) na abordagem de Mattessich não se hierarquizavam postulados,

princípios, normas. Todos são conceitos".

Conforme ensina Franco ${ }^{10}$ :

"Nem todos os autores são unânimes no critério de selecionar o que é postulado, o que é principio e o que é norma ou convenção, embora haja o entendimento uniforme de que os postulados e os princípios têm existência própria e precisam ser identificados e enunciados pelos doutrinadores, ao passo que as normas e as convensões são estabelecidas por eles, ou profissionais e órgãos reguladores de uma profissão, com a finalidade de orientar os profissionais no exercício de suas funções objetivando os fins da atividade exercida".

Em outra passagem do mesmo trabalho, o mestre apresenta a compreensão de que os princípios gerais seriam de dois tipos: 1) aqueles que caracterizam o ambiente ou as condições em que a Contabilidade atua, os quais existem independentemente da própria Contabilidade; 2) aqueles que decorrem da aplicação da Contabilidade ${ }^{11 "}$. Os princípios do primeiro grupo Franco declara serem "aqueles por alguns distinguidos com o titulo de postulados (...)". Esta é precisamente a posição do autor deste artigo e uma das idéias centrais, que serve para reforçar a idéia da imutabilidade do núcleo central da teoria cientifica, também defendida por Franco na obra citada.

\footnotetext{
${ }^{9}$ IUDíCIBUS, Sérgio de. Op. Cit..,p. 49.

${ }^{10}$ FRANCO, Hilário, Op. Cit.., p. 20.

${ }^{11}$ Idem, ibidem, p. 24.
} 
No entendimento do American Institute of Certified Public Accountants - AICPA ${ }^{12}$.

"Os postulados são poucos em numero e constituem-se nos pressupostos básicos sob os quais os princípios repousam. Eles são necessariamente derivados do ambiente econômico e político, do modo de pensamento e dos costumes de todos os segmentos da comunidade de negócios. A profissão, contudo, deve tornar claro o seu entendimento e interpretação do que são esses postulados, para prover uma base significativa de princípios e o desenvolvimento de regras ou outras guias para aplicação (...)".

Hendriksen adverte sobre a impropriedade de manter os postulados implícitos, supor ou seu conhecimento, consentimento ou acordo geral; atenta sobre a necessidade e importância dos postulados serem enunciados e expressos com clareza para que as eventuais divergências de interpretação possam ser trazidas a publico e devidamente solucionadas, posto (...) que se não estão adequadamente respaldados, as conclusões deduzidas dele só podem ser tentativas ${ }^{13}$." Ainda reforçar a necessidade da enunciação dos postulados, Hendriksen fala sobre a possibilidade que o postulado tem de ser falsificável, isto é, ser demonstrado falso e posteriormente rejeitado, mesmo que geralmente aceito. Esta possibilidade de ser falsificável é na realidade uma propriedade dos enunciados científicos, quando se Ihes exige objetividade, clareza, conteúdo declaratório explicito, de forma que não existam duvidas sobre suas afirmações. Este conceito será explorado mais adiante neste trabalho, sob o titulo Estrutura Fundamental da Teoria Contábil”. No parágrafo que segue, é reproduzida a contribuição de Hendriksen ${ }^{14}$ para o fechamento deste tópico.

"Em resumo, pois, os postulados são suposições básicas ou preposições fundamentais concernentes ao meio econômico, político e sociológico em que tem que operar a Contabilidade. Os critérios básicos são que: 1) tem que ser relevantes ao desenvolvimento da lógica da Contabilidade; isto é: tem que servir de fundamento para a dedução lógica de preposições adicionais, e 2) têm que ser aceitos como validos pelos participantes da discussão, ora por serem certos ou proporcionar um útil ponto de partida, como assunção no desenvolvimento da lógica da Contabilidade".

Neste ponto, esperava-se haver contribuído para a apresentação dos pressupostos, necessários como sedimento para as etapas que seguem:

- os postulados formam o núcleo básico da teoria, constituindo-se na orientação primária de toda a sua construção;

- devem ser explicitados de forma de forma que não haja duvida quanto a seus pressupostos fundamentais e de forma a permitir amplo julgamento da validade lógica de suas proposições.

Deve-se reforçar ainda a questão formulada por Hendriksen de que o postulado deve se permitir a prova da falsificação.

\section{Entidade}

Segundo a contribuição de Hendriksen ${ }^{15}$ :

"Quase todos o jogos de postulados e conceitos incluem suposições referentes ao caráter da Contabilidade. A razão principal da importância deste conceito é que define o campo de interesse e dessa maneira restringe os possíveis objetos e atividades e seus atributos que podem selecionar-se

\footnotetext{
${ }^{12}$ WIXON, Rufus, KELL, Walter G. BEDFORD, Norton M. Accountants Handbook, 5 ed., New York: The Ronald Press Company, 1970, p. 12.

${ }^{13}$ HENDRISKEN, Eldon S. Op..cit.,p. 110-111.

${ }^{14}$ Idem, ibidem, p. 112.

${ }^{15}$ HENDRISKEN, Eldon S. Op..cit., p. 114.
} 
para inclui-los em informes financeiros. Ademais, os postulados que se relacionam com o caráter da entidade podem também restringir mais a seleção do que incluir nos informes e ajudar a determinar como apresentar melhor a informação concernente à entidade, de modo que se revelem os traços pertinentes e de maneira que os traços impertinentes não obscureçam a informação básica".

Neste texto, o postulado da Entidade é apresentado através de dois enfoques básicos: o enfoque econômico (incluir-se-ia aqui o chamado enfoque jurídico, visto como de mesma natureza que o econômico) e o enfoque da informação. O primeiro é defendido por Moonitz ${ }^{16}$, "Atividades econômicas são conduzidas por unidades especificas ou por entidades" e por Mattessich", "Existe um conjunto de entidades que constitui a estrutura para as ações econômicas".

No segundo enfoque, as fronteiras seriam definidas de acordo com a esfera de interesse informativo dos usuários para os quais a informação é dirigida. Segundo o comitê sobre estudos de investigação de Conceitos e Normas da Associação Norte Americana de Contabilidade de 1994, citado por Hendriksen ${ }^{18}$, "as fronteiras de tal entidade econômica são identificáveis: 1) 1) pela determinação da pessoa ou grupo interessado, e 2) pela determinação do caráter desta pessoa ou o interesse desse grupo".

A diferença entre os dois enfoques é contrastada por Hendriksen ${ }^{19}$ no parágrafo que segue. Reforça-se a importância de observar as causas atribuídas à variação de foco posta a descoberto pelo autor.

"Ambos enfoques podem conduzir às mesmas conclusões, porém o enfoque orientado para os usuários pode levar uma seleção de informação que seja diferente do enfoque baseado na atividade econômica; e pode estender as fronteiras da entidade de forma que inclua alguma atividade ambiental, tal como as tentativas de melhorar as relações sociológicas dentro da empresa ou comunidade e a informação concernente ás responsabilidades sociais da empresa(...) A eleição da entidade apropriada e a determinação de suas fronteiras depende dos objetivos dos informes e dos interesses dos usuários da informação apresentada".

Aqui, e alcançado um dos principais objetivos deste ensaio, demonstrar que: a forma como os postulados fundamentais estão explicitados permite uma variedade bastante perceptível de interpretações, conforme a ótica particular de cada observador, como se fosse uma refração primaria na definição do foco, que necessita de um ajuste conceitual, e que será abordado oportunamente.

$\underline{\text { Continuidade }}$

Segundo Hendriksen ${ }^{20}$ :

Uma observação adicional pertinente que se faz geralmente em relação com o caráter da entidade contábil e que quase todas as unidades econômicas se organizam para operar durante um tempo indefinido. Por conseguinte, se argumenta freqüentemente, que e um passo lógico para reconhecer que a entidade deve ser vista como operando indefinidamente sob circunstâncias normais (o postulado tradicional do negocio em marcha). ... A continuidade supõe alguma conexão entre o passado e o futuro. ainda que nem sempre o futuro seja uma reiteração do passado. No caso de uma descontinuidade, tal como uma liquidação forçosa, os procedimentos de Contabilidade habituais não seriam aplicáveis e o Contador deve revelar o caráter da descontinuidade".

Na seqüência, Hendriksen ${ }^{21}$ destaca que Moonitz procura qualificar o postulado da continuidade

\footnotetext{
${ }^{16}$ MOONITZ, Maurice The Basic Postulates of Accounting. Na Accounting Research Study, n. 1, New York: American Institute of Certified Public Accountants - AICPA, 1961.

${ }^{17}$ MATTESSICH, Richard. Accounting and Analytical Methods. Illions: Richard D. Irwin Inc, 1964, p. 37.

${ }^{18}$ HENDRISKEN, Eldon S. Op..cit., p. 115.

${ }^{19}$ Idem , ibidem, p. 115.

${ }^{20}$ HENDRISKEN, Eldon. Op..cit., p.116.

${ }^{21}$ Idem, ibidem. Ibidem.
} 
como imperativo em decorrência da falta de acordo geral sobre o seu fundamento, entre outras razoes encontradas na literatura contábil e, na opinião do autor leste artigo por não ser fundamentalmente um atributo da Entidade.

Ainda segundo Hendriksen ${ }^{22}$, ljiri e Sterling não declaram a existência de um postulado da Continuidade, ou por considerá-lo desnecessário ou ainda, inconveniente.

Enfatisa-se a importância fundamental deste postulado e se propõe ao postulado da Continuidade "assento cativo" no Núcleo Teórico Fundamental da Contabilidade; entretanto urge denunciar a fragilidade da fundamentação da Continuidade, apoiada em que está no postulado anterior.

Aqui a divergência de foco captada na enunciação do postulado da Entidade é realçada. Analogamente, o imperceptível desvio de ângulo em determinado intervalo de observação de duas retas torna-se progressivamente mais perceptível, conforme os seus limites são estendidos ao infinito, a ponto de negar um atributo de paralelas a elas inicialmente conferido. Ou seja, as diferenças, quase semânticas de interpretação do primeiro postulado, levam ao questionamento da validade do segundo.

De fato, a Continuidade não é um atributo que possa ser conferido à Entidade e as observações empíricas, que não requerem citação por serem de conhecimento geral, o provam, tornando o relacionamento Entidade $\mathrm{x}$ Continuidade falseado.

\section{Análise da Estrutura do Núcleo Fundamental da Teoria Contábil}

Neste ponto ensaia-se uma análise da estrutura conceitual básica da Contabilidade, conforme as criticas anteriores, feitas neste trabalho, acerca da deficiência de foco notada na definição dos postulados.

Introduz-se aqui, sumariamente, o ponto de vista de uma das escolas dos teóricos da ciência, de como as suposições científicas devem possuir o atributo de falsificáveis isto é, devem possuir um conteúdo declaratório, tal que permita toda a sorte de provas posteriores no sentido de testar a sua validade. Esta característica básica das afirmações válidas para a ciência é que conferiria aos postulados, credibilidade, e que permitiria a evolução to do conhecimento científico, pela refutação de pressuposições falseadas e manutenção de outras.

A este respeito reproduz-se uma crítica de Chalmers ${ }^{23}$ ao falsificacionismo, aonde, apesar da sua contestação da validade do falsificacionismo como reprodutor em si do conhecimento científico, reconhece seus métodos, entretanto, para a submissão de prova a uma teoria.

"O falcificacionista ingênuo insiste em afirmar que a atividade científica deve estar preocupada com as tentativas de falsificar teorias estabelecendo a verdade das proposições de observação que sejam inconsistentes com elas. O falcificacionista mais sofisticado percebe a inadequação desta idéia e reconhece a importância do papel desempenhado pela confirmação das teorias especulativas bem como pela falsificação das teorias bem estabelecidas. Uma coisa que ambos os tipos de falcificacionista têm em comum, entretanto, é que há uma importante diferença qualitativa nos status das confirmações e das falsificações. As teorias podem ser conclusivamente falsificadas à luz das provas disponíveis, enquanto não podem jamais ser estabelecidas como verdadeiras ou mesmo provavelmente verdadeiras qualquer que seja a prova. A aceitação da teoria é sempre uma tentativa. A rejeição da teoria pode ser decisiva. Este é um fator que faz com que os falsificacionistas mereçam seu título".

Procurando introduzir rapidamente as idéias que permeiam o falsificacionismo, como método reconhecidamente válido para teste e refutação das teorias científicas, visto que nesta análise dos

\footnotetext{
${ }^{22}$ Idem, ibidem, p. 117.

${ }^{23}$ CHALMERS, A.F. O que é a Ciência Afinal? São Paulo: Brasiliense, 1993, p. 90.
} 
postulados contábeis, verifica-se que o Postulado da Continuidade é falsificável, na forma como é enunciado.

Chalmers remete à dependência que a boa observação tem da teoria, tanto mais acurada quanto o forem os referenciais de observação. A teoria brinda ao pesquisador um ponto de apoio. de forma que sua atenção é dirigida a um foco minimamente especificado.

Em continuação, procura-se realçar a importância que Chalmers ${ }^{24}$ atribui à organização da estrutura teórica para o desenvolvimento do conhecimento científico.

"Mencionamos até agora dois motivos para que as teorias devam ser vistas como estruturas organizadas de alguma espécie: o fato do estudo histórico demonstrar que as teorias possuem essa característica e o tato que e somente por meio de uma teoria coerentemente estruturada que os conceitos adquirem um sentido preciso. Um terceiro motivo tem origem na necessidade da ciência de crescer. Está claro que a ciência avançará mais eficientemente se as teorias forem estruturadas, de maneira a conter em seu interior indícios e receitas bastante claros quanto a como elas devem ser desenvolvidas e estendidas. Elas devem ser estruturas abertas para que ofereçam um programa de pesquisa. A mecânica de Newton forneceu um programa para os físicos dos séculos XVIII e XIX, o programa para explicar todo o mundo físico em termos de sistemas mecânicos que envolvem várias forcas e são governados pelas leis de movimento de Newton".

Prosseguindo com a síntese do que Chalmers ${ }^{25}$ denominou como: uma tentativa notável de analisar teorias enquanto estruturas organizadas, a "Metodologia dos Programas de Pesquisa Científica"de Imre Lakatos.

"Um programa de pesquisa lakatosiano e uma estrutura que fornece orientação para a pesquisa futura de uma forma tanto negativa quanto positiva. A heurística negativa de um programa envolve a estipulação de que as suposições básicas subjacentes ao programa, seu núcleo irredutível, não devem ser rejeitadas ou modificadas. Ele esta protegido da falsificação por um cinturão de hipóteses auxiliares, condições iniciais, etc. A heurística positiva é composta de uma pauta geral que indica como pode ser desenvolvido o programa de pesquisa. Um tal desenvolvimento envolverá suplementar o núcleo irredutível com suposições adicionais numa tentativa de explicar fenômenos previamente conhecidos e prever fenômenos novos. Os programas de pesquisa serão progressivos ou degenerescentes, dependendo do sucesso ou fracasso persistente quando levam a descoberta de fenômenos novos".

"O núcleo irredutível de um programa é, mais do que qualquer outra coisa, a característica que o define. Ele assume a forma de alguma hipótese teórica muito geral que constitui a base a partir da qual o programa deve se desenvolver. Aqui estão alguns exemplos. O núcleo irredutível da astronomia copernicana seriam as suposições de que a Terra e os planetas orbitam um sol estacionário e que a Terra gira em seu eixo uma vez por dia. O núcleo irredutível da física newtoniana é composto das leis do movimento de Newton mais a sua lei de atração gravitacional. $O$ núcleo irredutível materialismo histórico de Marx seria a suposição de que a mudança histórica deva ser explicada em termos de lutas de classes, a natureza das classes e os detalhes da lutas sendo determinados, em última análise, pela base econômica".

Neste ponto encontra-se os argumentos que reforçam a premissa que deu origem a este ensaio:

o núcleo teórico fundamental da Contabilidade deve ser permanente e imutável, posição que encontra firme respaldo em Franco ${ }^{26}$.

Esta posição confortável, em principio, seria possível pela notável evolução técnica alcançada pelos pressupostos contábeis fundamentais, com uma pequena alteração.

Na próxima seqüência, procura-se introduzir uma "vacina" para os pressupostos contidos nos

\footnotetext{
${ }^{24}$ Idem, ibidem, p. 112.

${ }^{25}$ Idem, ibidem, p. 113.

${ }^{26}$ FRANCO, Hilário . Op. Cit., p.24.
} 
postulados contábeis, reafirmando-os assim, contra ás incursões falsificacionistas.

\section{Proposição para Classificação dos Postulados em Contabilidade}

\section{Uma Articulação em Teoria Geral dos Sistemas}

O Universo em sua acepção mais ampla, é o campo de observação e atuação de todas as ciências.

Universo é um conceito não completa ou adequadamente definido dadas as suas "fronteiras", por princípios inexistentes, isto é, contém todos os demais conjuntos que se poderiam conceber.

A aceitação do Universo como campo primário de observação, em que pese a restrição quanto á sua adequada definição, justifica-se pela necessidade da existência de limites pré instituídos á observação cientifica. Isto é, parte de um interesse sobre tudo o que esta contido no Universo, dado a vastidão dos seus domínios, o estudo cientifico procede à segregação de áreas de interesse, de forma a organizar atividade de pesquisa, disciplinar o deslumbramento do cientista perante o mundo. Esta segregação obedece a atributos relevantes observados no ambiente de interesse de cada ramo de estudo cientifico. Neste sentido, a missão dos postulados constitui-se em promover a revelação (declaração) destes atributos relevantes e ainda em referencial, orientação primária do interesse cientifico em dado campo de conhecimento.

Considerando o Universo um amplo conjunto de elementos em relação sistêmica, a Teoria Geral de Sistemas candidata-se a desempenhar o papel de elo de ligação entre as ciências, por colocar a descoberto alguns princípios que regem as relações geradas em seu meio, e por constituir-se em mudança de paradigma, qual seja, a passagem da perspectiva de visão mecanicista ${ }^{27}$, para uma perspectiva de visão mais ampla, holística ${ }^{28}$, da consideração das partes e fenômenos isolados para a sua consideração em um contexto de relações sistêmicas.

Ao enfocar primariamente a Entidade, como objeto de estudo da Contabilidade, estabelece-se uma limitação, em princípio, no foco de observação, posto que the é colocada as seguintes fronteiras: a própria Entidade e a falta de reconhecimento explicito de sua relação sistêmica com o ambiente (designação eleita para o Universo neste campo de observação). Por que razão justificável há que se definir um ponto de partida para a Contabilidade diferente das demais ciências e por que não promover a correção? Quais seriam as conseqüências?

Em um primeiro momento, uma melhor definição uma melhor definição do foco, como anteriormente mencionado e em segundo, a admissão explicita das relações sistêmicas neste campo de estudo, Bertalanffy ${ }^{29}$, apresenta a seguinte citação de Kuhn, acerca das mudanças de paradigma introduzidas pela Teoria Geral de Sistemas:

"(...) uma revolução cientifica define-se pelo aparecimento de novos esquemas ou paradigmas conceituais. Estes põem em evidência aspectos que não eram anteriormente vistos nem percebidos, ou eram mesmo suprimidos na ciência normal, isto é, a ciência geralmente aceita a praticada no momento. Por conseguinte há um deslocamento nos problemas observados e estudados e uma mudança nas regras da prática cientifica, comparável á troca nas Gestalten perceptíveis nas experiências psicológicas".

A Teoria Geral de Sistemas apresenta o conceito de sistema aberto como principal atributo de

\footnotetext{
${ }^{27}$ Mecanismos: doutrina que admite que determinado conjunto de Fenômenos, (...) determinado por lei causal rigorosa (..)

${ }^{28}$ Holismo: tendência, que se supõe seja própria do universo, a sintetizar unidades em totalidades organizadas.

${ }^{29}$ BERTALANFFY, Ludwig von. Teoria Geral dos Sistemas. Petrópolis: Vozes, 1977, p. 36.
} 
sua enunciação, que é definido por Kleber T. Nascimento ${ }^{30}$.

"(...) como um conjunto de partes em constante interação ( o que ressalta a característica de independência das partes) constituindo um todo sinérgico (maior que a soma das partes) orientado para determinados propósitos (com comportamento teleológico orientando portanto para fins) e em permanente relação de independência com o ambiente externo (essa interdependência há de ser entendida como a dupla capacidade de influenciar o meio externo e ser por ele influenciado)."

Em seu estudo, Nascimento ${ }^{31}$ procura destacar qual a importância da ciência da Administração abraçar o novo enfoque, constituindo-se este na diferença entre garantir ou não a continuidade das organizações.

"(...) além das implicações conceituais da diferença entre as perspectivas de sistema fechado e de sistema aberto, é indispensável um breve comentário sobre as implicações pragmáticas, comportamentais, dessas perspectivas. Como sistema fechado, o fator primário do sucesso esta na adequação das relações internas entre pessoas, cargos e equipamentos, segue-se que os critérios", estruturas e métodos e comportamentos da organização (sistema) devem ser técnicas e princípios administrativos de eficiência interna, como o alcance do controle, a unidade de comando, as regras de departamentalização ou, em suma: são as necessidades internas ou de processamento que devem condicionar os critérios, estruturas. métodos e comportamentos da organização. Se, pelo contrario, o sucesso organizacional e percebido primariamente em função das relações da organização (sistema) e o seu ambiente, era função, pois, da capacidade de resposta da primeira ao segundo, então os fatores determinantes dos critérios. estruturas, métodos e comportamentos da organização serão programas - e não princípios - orienta-los para as necessidades externas - e não internas - programas estes que devem uma operacionalização das demandas do ambiente. Essa breve analise do relacionamento entre as novas realidades ambientais, organizacionais e gerenciais terá tornado mais fácil apreender as implicações de conceituar a administração (e, pois, o papel do administrador) como um sistema aberto ou como um sistema fechado. Tal diferença conceitual corresponde de certa forma, à diferença entre o executivo perceber o seu papel como inovador ou como mantenedor. A responsabilidade pela inovação só pode ser atribuída ao verdadeiro executivo, aquele que, tal como um sistema aberto, sustenta condições de reversibilidade, ou seja. mantém sua capacidade de aprendizagem".

Ao se propor o Postulado do Ambiente declara e para a Contabilidade a existência de um "sitio" em que se manifesta e esta contida a Entidade sujeita aos reflexos de todos os processos de interações que se dão neste meio. Assim, o Ambiente é o campo de observação da Contabilidade, a entidade.

Já o pressuposto de Continuidade, fundamental para o desenvolvimento da disciplina, é um atributo do Ambiente posto que a Entidade não pode ser considerada permanente, se não conseguir, através de um hábil relacionamento ambiental, garantir a sua sobrevivência.

Finalmente, caberia ressaltar o risco de enfocar unicamente o universo de relações partidas da Entidade para o Ambiente, desprezando aquelas relações muito mais amplas que seriam constituídas das influências partidas do Ambiente para a Entidade. Poderia a falta de enunciação explícita deste postulado (como o foram enunciados os demais, hoje suficientemente discutidos e elucidados), constituir-se em um problema de restrição ao adequado desenvolvimento do corpo de conhecimentos?

\section{Conclusões}

\footnotetext{
${ }^{30}$ NASCIMENTO, Kleber T. A Revolução Conceitual da Administração - Implicações para a Formulação dos Papéis e Funções Essenciais de um Executivo Público. Revista de Administração de Empresas. Rio de Janeiro, FGV, v. 6, 1972 , p. 34 ${ }^{31}$ Idem , ibidem.
} 
Entende-se que a Teoria da Contabilidade alcançou a sua maturidade nos termos atuais, apresentando uma estrutura teórica bem desenvolvida, comparativamente às demais ciências pesquisadas. oferecendo um núcleo conceitual seguro e bem definido, como orientação à pesquisa cientifica e prática profissional.

Cabe um senão quanto à necessidade de enunciação de um conjunto de princípios como um núcleo irredutível, e a afirmação explícita do compromisso com o estudo das relações ambientais de forma ampla.

Não se partilha da crença de que as ciências sociais devam ter referenciais cambiantes, conforme os interesses e objetivos de cada conjuntura sócia em particular. Deve-se estar atento aos interesses dos usuários, principais clientes dos serviços que só pode oferecer como resultado deste labor. Entretanto, é necessária a preservação do núcleo teórico primordial.

As premissas e pressupostos subjacentes devem ser acrescentados ao redor deste núcleo, estes sim, sujeitos aos câmbios conjunturais.

Assim, propõe-se a evolução do núcleo teórico fundamental para o composto de um objetivo e três postulados, como segue:

- Objetivo - o estudo do Ambiente, tendo as relações biunívocas deste com a Entidade, como referencial;

- Postulado do Ambiente - é o Universo, conjunto que contém todos os demais conjuntos, visto pela ótica da Contabilidade, ou seja, em que esta contida a Entidade e se processam todas as suas relações;

- Postulado de Entidade - similar a teoria atual, mas com ênfase não em aspectos econômicos ou de interesse na informação, e sim no agente que se relaciona passiva e ativamente com o ambiente;

- Postulado da Continuidade - como um atributo do ambiente e não da Entidade; naturalmente por uma questão de sobrevivência, é uma premissa á busca da perturbação das relações da Entidade com o Ambiente, ou a sua manutenção de conformidade com objetivos pré-definidos.

\section{Resumo}

Este ensaio tem como objetivo uma revisão da estrutura conceitual básica da Contabilidade, assim compreendidos os objetivos e postulados, enquanto satisfatório embasamento teórico para garantir o caráter cientifico da disciplina contábil, adequado guia para o desenvolvimento de novos conhecimentos, um fomento da pesquisa e um referencial para a pratica profissional, á luz da Teoria do Conhecimento.

O seu desenvolvimento cientifico e responsável pelo seu desenvolvimento;

- a teoria é o marco fundamental do conhecimento cientifico e responsável pelo seu desenvolvimento;

- este marco teórico fundamental não deveria conter orientação de caráter utilitário, a priori, de forma a não influir os desdobramentos de novas possíveis revelações;

- a Contabilidade é um campo de conhecimento desenvolvido a partir de um enfoque utilitário e, portanto, é suposta a possível limitação de alcance de suas bases teóricas, desenvolvidas como justificativa para as práticas geralmente aceitas;

- o desenvolvimento teórico contábil, assentado em um enfoque utilitário, poderia estar orientado para o passado, não contemplando as bases para o enfrentamento dos novos desafios constituídos nos intensos movimentos de transformação ambiental; 
- a ampla insatisfação dos usuários e contadores com a prática contábil e proliferação de criticas quanto a estrutura de suas bases teóricas poderia ensejar o esgotamento do paradigma em que se assenta sua base conceitual;

- a busca do conhecimento deve ser orientada sob um enfoque holístico com pressuposto básico para a captação das complexidades ambientais;

- a busca do desenvolvimento cientifico baseado na articulação de interesses interdisciplinares poderia atender, ao menos em parte, o requisito de uma visão holística ambiental;

- a articulação da Teoria Contábil com a Teoria Geral dos Sistemas poderia constituir-se em um novo paradigma para o desenvolvimento do conhecimento contábil e a reafirmação da Contabilidade como ciência;

- o núcleo fundamental da Teoria Contábil deveria constituir-se de um conjunto universal, irredutível e permanente de princípios, não subordinado a objetivos utilitários, que restringiriam a revelação de novos conhecimentos e aplicações.

A partir dessas premissas e suposições, efetuou-se uma análise das bases históricas da evolução da ciência contábil, passando pelas diversas influências recebidas em seu desenvolvimento, com ênfase no caráter utilitário de sua formação. Deste ponto, realçou-se a importância e conteúdo do seu marco conceitual básico, submetendo-o á análise e critica segundo algumas proposições formuladas pela Teoria do Conhecimento.

Finalmente, ensaiou-se uma articulação com a Teoria Geral de Sistemas, em que se propôs uma revisão dos princípios de Contabilidade, á luz da reforma de seus postulados fundamentais e objetivos.

Como conseqüência, espera-se abrir caminho para uma reflexão acerca da inserção da problemática ambiental para a Ciência Contábil, em nível de postulados; possibilitar a declaração de um núcleo teórico, a principio, permanente e irredutível; permitir a sua generalização para todos os ramos de especialização da Contabilidade, atualmente "órfãos" de um acordo geral de princípios, afora a Contabilidade Financeira.

Referências Bibliográficas

AICPA - American Institute of Certified Public Accountants, Professional Standards, v.3. New York, 1977 ANTHONY - N.Robert. Contabilidade Gerencial. São Paulo: Atlas, 1970.

BARNES Barry, KUHN, Thomas S., MERTON, Robert K. e Otros. Estúdios sobre Sociología de La Ciência. Madrid: Alianza Editorial S.A., 1.980,

BERTALANFFY, Ludwig von, Teoria Geral dos Sistemas. Petrópolis: Vozes: 1.977

CHALMERS, A.F. O que é a Ciência afinal? São Paulo: Brasiliense, 1993.

FIPECAFI. Fundação Institutos de Pesquisas Contábeis, Atuariais e Financeiras. Manual de Contabilidade das Sociedades por Ações. 4. ed. São Paulo :Atlas, 1995.

FRANCO, Hilário. A Evolução dos Princípios Contábeis no Brasil. São Paulo: Atlas, 1988

HENDRIKSEN, Eldon S. Teoria de La Contabilidad México Unión Tipografía Editorial Hispano-b Americana, 1970.

IBRACON - Instituto Brasileiro de Contadores. Princípios Contábeis e Normas de Procedimentos de Auditoria. São Paulo : Atlas, 1988. 
IUDICIBUS, Sergio de. Teoria da Contabilidade São Paulo: Atlas, 1980.

JOHNSON, Thomas H. e KAPLAN, Robert S. Contabilidade Gerencial. Rio de Janeiro: Campus, 1993.

MATTESSICH, Richard. Accounting and Analytical Methods Illinois: Richard D. Irwin Inc.,1964,

IUDICIBUS, Sergio de. Teoria da Contabilidade São Paulo: Atlas, 1980.

MOONITS, Maurice. Obtaining Agreement on Standards in the Accounting Profession, Studies in Accounting Research, N.8 Sarasota: American Accounting Association, 1974.

MOONITZ, Maurice. The Basic Postulates of Accounting Research Study, N.1, New York: American Institute of Certified Public Accountants, AICPA, 1961.

MOST, Kenneth, Accounting Theory 3.ed., Illiniois Irwin, 1977

NASCIMENTO, Kleber T.A Revolução Conceitual da Administração - Implicações para a Formulação dos Papeis e Funções Essenciais de um Executivo Publico. Revista de Administração de Empresas, Rio de Janeiro, FGV. V. 6, 1972,

2 BARNES Barry, KUHN, Thomas S., MERTON, Robert K. e Otros. Estúdios sobre Sociología de La Ciência. Madrid: Alianza Editorial S.A., 1.980, p.43.

WIXON, Rufus, KELL, Walter G., BEDFORD, Norton M. Accountants Handbook. 5. ed., New York: The Ronald Press Company, 1970

WILLIAMS, Jan. R. GAAP. Guide a Comprehensive Restatement of Current Promulgated Generally Accepted Accounting Principles. New York: Harcourt Brace \& Company, 1977. 